\title{
THE EVALUATION OF VISION IN CHILDREN USING MONOCULAR VISION ACUITY AND STREREO-ACUITY TESTS
}

BY

*EMINA, M. O. AND OSAIYUWU, A. B. DEPARTMENT OF OPTOMETRY, UNIVERSITY OF BENIN, BENIN-CITY, NIGERIA.

*Corresponding author

\section{ABSTRACT}

Monocular visual acuity and stereo-acuity tests were carried out on 308 children between the ages of two to twelve years. Children with reduced visual acuity (V.A) and who failed the Random Dot E (RDE) stereo- acuity tests were further examined for associated eye problems. $308(97.7 \%)$ children were tested for monocular visual acuity, 287(93.8\%) children for RDE stereo-acuity and 263 (85.4\%) for Randot circles stereo-acuity test. Reduced visual acuity was found in $38(12.3 \%)$ children and $3(1 \%)$ children were blind in one eye. $21(26.8 \%)$ children who failed stereo-acuity had ocular problems and $17(5.5 \%)$ children failed both stereo-acuity and monocular visual acuity tests. There was no significant difference between preschool and school aged children with reduced V.A $\left(\mathrm{Z}_{\mathrm{cal}}=1.047, \mathrm{Z}_{\text {tab }}=3.84\right)$. It is thus useful that monocular visual acuity and stereopsis eye examination be part of the routine eye examinations for children.

KEYWORDS: Stereo-acuity. Random DotE, Random circles, Stereopsis, Amblyopia.

\section{INTRODUCTION}

Monocular visual acuity (VA) is a direct method of detecting amblyopia, a leading cause of monocular vision loss in the 2 to 7 years age group ${ }^{1}$. Binocular vision is fully established by 6 moths of age, while fusion is consistently strengthened until the age of 6 years when it is fully developed ${ }^{2}$. It was observed that monocular deprivation could cause significant loss of vision as a result of its effect on the anatomy, physiology and function of the visual pathway, during the early sensitive period of life. In children under the age of 7 years, the brain can ignore one of two images leading to monocular vision. If this condition continues for days or weeks in younger children and for months in older ones, the visual pathway may fail to develop properly, resulting in amblyopia. ${ }^{2}$

Stereopsis testing specifically detects strabismus as an amblyogenic factor. A high level of stereo acuity also confirms good and equal binocular vision but does not allow determination of VAin the usual sense ${ }^{3}$. Despite the importance of early vision screening for strabismus and amblyopia, detecting ocular disorders in children less than three years of age have generally been unsuccessful. This is due to the child's inability to cooperate during eye examination; resulting to insufficient time for the test and inaccuracy of the test results. However, some of the techniques for this age group such as preferential looking, grating acuity cards, refractive screening and photographic evaluation have not yet been proven effective ${ }^{4}$. VA is reduced due to refractive error or ocular disease leading to poor vision or complete loss of vision. Any obstacle to normal development of vision early in life is often reflected in the level of stereo acuity attained. Stereopsis should be therefore a useful method of evaluating the level of binocular vision present in children. It had been demonstrated that either stereopsis or normal monocular acuity could rule out the presence of any gross visual anomaly ${ }^{5}$ Therefore, the appropriate use of this test will facilitate the early detection of any abnormality.

Fern and Manny ${ }^{6}$ studied VA of preschool children and discovered that stereogram test such as Random Dot E (RDE) was more effective than VA test in detecting strabismus and amblyopia. Broadbent and $\mathrm{Westal}^{7}$ evaluated also the techniques for measuring stereopsis in infants and young children and concluded that stereopsis was a valuable test in vision screening of infants and toddlers, because it ruled out profound visual defects.

\section{METHOD}

The written and oral consents of the parents or guardians of the children were obtained and the institutional consent for children under school age was also obtained from their school authority 
before commencing the eye examination.

Children between the ages of 2-12years were examined. Monocular VA test (both at distance and near) and stereo acuity test at near were carried out. Children that failed the RDE stereo test and those that had poor or subnormal vision greater than one line difference (6/9 line) were subjected to further test such as penlight examination, cover test, ophthalmoscopy, retinoscopy and subjective refraction.

\section{RESULTS}

In this study, 308 subjects consisting 148 (48\%) males and $160(52 \%)$ females were tested for monocular VA. RDE and Randot circles stereoacuity tests were carried out on the participant. It was found that 52 males and 41 females did not cooperate in one or some of the tests by either refusing to talk or refusing occlusion and not wanting to put on the polarized glasses. The mean age of all the children examined was $6.9 \pm 2.2$ years. The mean age for the males was 7.2 \pm 1.9 years and that of the females was $6.5 \pm 2.5$ years.

All the tests were administered on every child, except for the children who did not cooperate for a particular eye examination. It was found that $38(12.34 \%)$ children had reduced monocular acuity. They consist of $17(5.5 \%)$ males and $21(6.8 \%)$ females (table 1). Reduced VA of less than or equal to $6 / 12$ in one or both eyes was found in 38 children, $17(5.52 \%)$ males and $21(6.82 \%)$ females. Standard VA of $3 / 6$ and 3/9 for children under 4years of age were found in 270 children. The children with standard VA consist of $130(42.53 \%)$ males and 140(45.13\%) females (table 1).

The $301(97.7 \%)$ children that participated in the monocular acuity test were $143(46.4 \%)$ males and $158(51.3 \%)$ females. It was found that $38(12.34 \%)$ of the children failed the VA test (table 2).

The $263(85.4 \%)$ children that had the RDE stereo-acuity test, $20(6.2 \%)$ children did not cooperate in the RDE test; they were mostly under 3 years of age. The Randot circles stereo-acuity test was carried out on children that passed the RDE test. In all, 263 children that had the RDE test attempted the Randot circles stereo-acuity test and they consist of $122(46.39 \%)$ males and 141 $(53.61 \%)$ females. The children had threshold stereo-acuity between 20 to 140 seconds of arc with the Randot circles test. 197 (75\%) children participated in the Randot circles stereo-acuity test and $66(25.1 \%)$ children did not cooperate during the test. The 66(25.1\%) children did not understand and they were under 6years of age (table 3 ).

There was no significant difference in reduced VA between males and females $\left(\mathrm{Z}_{\text {cal }}=0.063, \mathrm{Z}_{\mathrm{tab}}=\right.$ 3.84 , at 0.05 confidence level). It was observed that $20(6.5 \%)$ children between 2 to 6years of age had reduced visual acuity (table 2). There was no significant difference in reduce VA between preschool and school aged children in the population $\left(\mathrm{Z}_{\mathrm{cal}}=1.33, \mathrm{Z}_{\mathrm{tab}}=3.84\right.$, at 0.05 confidence level).

Nevertheless, 24(8.3\%) children failed the RDE test and 215 children passed the test. However, all the children were asked to participate in the RDE test. It was only 243 children that passed the VA test that willingly attempted the RDE test (table3). There was no significant difference between male and female children that failed the RDE stereo-acuity test $\left(\mathrm{Z}_{\text {cal }}=1.047\right.$, $\mathrm{Z}_{\mathrm{tab}}=3.84$ ).

Thirty eight children with reduced VA failed also the RDE stereo-acuity test and they were further examined in order to verify the cause of their poor vision. It was observed that the thirtyone (31) subjects had various types of ocular anomalies (table 4). The reason why the seven other children failed the test could not be ascertained with the ophthalmoscope and they were suspected to be amblyopic. It was also found that a male, 4years of age, passed the stereo-acuity test with a reduced acuity of 6/9 and he was esotropic. Sixteen children with reduced VA failed to obtain the desired stereo-threshold. Table 5 showed the result obtained with both the RDE test and the Randot circle test. It was observed that 31 children had various forms of visual anomalies and the pre-school age group with visual anomalies were in higher proportion than the school age children, but there was no significant difference between pre-school and school aged children that failed the RDE stereo-acuity test $\left(\mathrm{Z}_{\text {cal }}=1.33, \mathrm{Z}_{\text {tab }}=\right.$ 3.84).

\section{DISCUSSION}

The ocular examination of pre-school and school age children interest only few eye care practitioners. Children at the preschool age group disuse their eyes, which may lead to eye problems and result eventually to dropping out of school and unable to fulfill their potentials in life. There is need to assess the vision in order to know how best to help at this stage of life.

A total of 308 children participated in the test, but $301(97.7 \%)$ of the children had the monocular 
VA test. It was observed that $2.3 \%$ of children did not co-operate during VA (table 1). It was also found that $6.2 \%$ of the children did not co-operate during the RDE stereo acuity test and they were all under 3years of age (table 2). The recommendation by the expert panel reported by Hartman et $\mathrm{al}^{8}$ was to use linear acuity for RDE stereo acuity for 3-6 years old. It was observed that children between 4 to 8 years of age, who did not cooperate, understood not the test. Ciner et $\mathrm{al}^{9}$ suggested that attention factor play a significant role in stereoacuity testing and they found that $50 \%$ of the children within two years of age were successfully tested for monocular VA. They had also $97 \%$ success stereo-acuity testing with children within 3 yeas of age.

Visual anomalies detected were more in the females between 5 to 8 yeas of age (table 4 ). Visual anomalies due to reduced VA were mainly refractive errors. Children who failed stereo-acuity test and had reduced vision were due to mainly pathological defects (table 5). Anomalies detected by failing only the RDE stereo-acuity test were mainly cases of ocular deviation and amblyopia. Jundal $^{10}$ showed the pattern of visual disorders in rural and urban children and found that $91.27 \%$ of the children had better than 6/9 VA. In the present study, similar result to that of Junda ${ }^{10}$ was obtained. It was found that $90.7 \%$ of the children had normal (6/9) VA. Fern and Manny ${ }^{6}$ found that stereogram such as RDE was more effective than the VA test in the detection of strabismus and amblyopia. Their statement described what was observed in the current study and it was also observed that $21(87.5 \%)$ of the children who failed stereo-test had ocular anomalies. Nevertheless two (12.5\%) children who had no obvious ocular abnormality observed that 7 (29. $17 \%$ ) children who passed stereo-acuity test had poor monocular VA. The Randot circle test is more difficult to administer on children and may require longer time to teach the children all they required to know, because of its high demand on the children's attention. Therefore, a better preliminary test to eliminate possible ocular anomalies can be achieved with test similar to RDE test and monocular VA. The visual system is vitally important for learning and early detection of vision problems can help the child achieve his potentials in life.

TABLE 1: DISTRIBUTION OF REDUCED V.A IN

MALES AND FEMALES PARTICIPANTS

\begin{tabular}{|l|l|l|l|}
\hline Population & Reduced VA & Standard VA & Total \\
\hline Males & 17 & 133 & 145 \\
\hline Females & 21 & 140 & 155 \\
\hline Total & $38(12.34 \%)$ & $270(87.66 \%)$ & $308(100 \%)$ \\
\hline
\end{tabular}

TABLE 2: $\quad$ DISTRIBUTION OF REDUCED V.A IN PRESCHOOL AND SCHOOL AGED CHILDREN

\begin{tabular}{|l|l|l|l|}
\hline Age & Reduced VA & Standard VA & Total \\
\hline $2-$ 6years & 20 & 131 & 151 \\
\hline 7 ï 12years & 18 & 139 & 157 \\
\hline & $38(12.34 \%)$ & $270(87.66 \%)$ & $308(100 \%)$ \\
\hline
\end{tabular}

TABLE 3: NUMBER OF MALE AND FEMALE CHILDREN THAT PARTICIPATED IN THE RANDOM CIRCLE STEREO -ACUITY TEST

\begin{tabular}{|l|l|l|}
\hline & Number of children examined & Percentage (\%) \\
\hline Male tested & 88 & 33.5 \\
\hline Males who did not understand the test & 34 & 12.9 \\
\hline Female tested & 109 & 41.5 \\
\hline Females who did not understand the test & 32 & 12.2 \\
\hline Total & 263 & $100 \%$ \\
\hline
\end{tabular}


NBWINA, ML O. AND OSATYUVU, A B.

TABLE 4: DISTRIBUTION OF CHILDREN TESTED WITH

STEREO-ACUITY TESTS AND MONOCULAR V.A TEST

\begin{tabular}{|l|l|l|}
\hline & Children with poor vision & Children with ocular anomalies \\
\hline Children that failed both tests & $17(43.2 \%)$ & $16(42.1 \%)$ \\
\hline Children who reduces V.A & $12(32.4 \%)$ & $9(23.7 \%)$ \\
\hline Children who failed RED test & $8(21.6 \%)$ & $5(13.2 \%)$ \\
\hline $\begin{array}{l}\text { Children who failed the test } \\
\text { due unknown cause }\end{array}$ & $7(18.4 \%)$ & - \\
\hline $\begin{array}{l}\text { Children who passed all the } \\
\text { test but had visual defect }\end{array}$ & $1(2.6 \%)$ & $1(2.6 \%)$ \\
\hline TOTAL & 38 & $31(81.6 \%)$ \\
\hline
\end{tabular}

TABLE 5: VISUAL ANOMALIES OBSERVED IN PER-SCHOOL AND AGE CHILDREN BY RDE AND RANDOM TESTS

\begin{tabular}{|l|l|l|}
\hline Age groups & Children with anomalies & Children without anomalies \\
\hline $2-6$ years & 16 & 136 \\
\hline $7-12$ years & 15 & 127 \\
\hline Total & 31 & 263 \\
\hline
\end{tabular}

\section{R E F E R E N C E S}

1. Broderick, P. (1998): Pediatric vision screening for the family Physician. Am. Acad. Fam. Physicians, 5.

2. Ciuffreda, K. J., Dennsi, M. L. and Arkady, S. (1991): Amblyopia: Basic and Clinical Aspects. $1^{\text {st }}$ edn. Butterworth Heinemann, USA, pp 44-61.

3. Stephen, S. F. and Reiecken, R. D. (1978): Handbook of pediatric Ophthalmology. Grane and Stratton, USA, pp4-5

4. Jacobson, P., Kvamstrom, G. and Lennerstrand, G. (1998): Screening for visual and ocular disorders in children, evaluation of the system in Sweden. Acta Paediat, 87: 11739.

5. Shute, R., Rowan, C., Westal, C. and Margaret, W. (1990): Success rates in testing monocular acuity and stereopsis in infants and young children. Ophthalmol. Physiol. Optics, 10: 133-8.
6. Farm, K. D. and Manny, R. E. (1986): Visual acuity of preschool children: A review. Am. J. Optom. Physiol. Optics, 63:319-45.

7. Broadbent, H. and Westal, C. (1989): An evaluation of techniques for measuring stereopsis in infants and young children. Ophthalmic Physiol. Optics, 10:3-7.

8. Hartman, E. E., Velma, D., Louise, H., Wendy, M., Graham, E. O., Mark, S. R., Schmidt, P. and Simons, K. (2000): Special Article: preschool vision screening summary of a Task force Report on pediatric. Am. Acad. Paediatr, 106 (5): 1105-16.

9. Cinder, E. B., Dobson, V., Schmidt, P. and Allen, D. A. (1999): Survey of vision screening policy of preschool children in the United States. Surv. Ophthalmic, 43: 445-7.

10. Jundal, A. (2002): Pattern of ocular and visual disorder in rural and urban community. Com. Ophthalmol,AIOC proceedings.. 